\title{
REFLEXÕES ACERCA DA EDUCAÇÃO FÍSICA NA ATUALIDADE
}

\section{REFLECTIONS ABOUT PHYSICAL EDUCATION TODAY}

\author{
Rosa Jussara Bonfim Silva ${ }^{1}$ \\ https://doi.org/10.29327/216986.1.1-8
}

RESUMO: O presente estudo teve como objetivo analisar a relação entre a eficácia dos conteúdos aplicados pelos professores nas aulas de educação física e os objetivos gerais dessa disciplina, no ensino fundamental, propostos pelos PCNs. A amostra Foi composta por 26 professores de educação física das séries finais do ensino fundamental, dos sexos feminino e masculino na faixa etária de 20 a 55 anos que trabalham nos turnos matutino e vespertino com carga horária de 18 e 36 horas (dois cargos), de uma população de 45 professores de educação física do ensino fundamental da Rede pública de Ensino de João pinheiro-MG e de Paracatu -MG. Pode-se concluir que grande parcela dos educadores pesquisados concorda parcialmente com os efeitos das aulas de Educação Física, em relação à formação de seus alunos, prevista nos objetivos gerais dos PCNs. Portanto apesar da nova reformulação dos padrões políticos e educacionais da disciplina, há ainda algumas dificuldades encontradas em sua aplicação no contexto escolar

Palavras - Chave: Educação, Educação Física, Aprendizagem.

ABSTRACT: This study aimed to analyze the relationship between the effectiveness of the content applied by teachers in physical education classes and the general objectives of this discipline, in elementary education, proposed by the PCNs. The sample consisted of 26 physical education teachers from the final grades of elementary school, male and female, aged between 20 and 55 years old who

\footnotetext{
1 Doutora em Educação pela Universidade Católica de Brasília - UCB. Pedagoga, professora e Coordenadora do Curso de Pedagogia da Faculdade do Noroeste de Minas - FINOM. http://lattes.cnpq.br/0517477118576942 https://orcid.org/0000-0002-2714-232X. E-Mail: rosajussarabonfim@gmail.com
} 
work in the morning and afternoon shifts with a workload of 18 and 36 hours (two positions), of a population of 45 physical education teachers from elementary school in the Public Education Network of João pinheiro-MG and Paracatu -MG. It can be concluded that a large portion of the educators surveyed partially agree with the effects of Physical Education classes, in relation to the training of their students, provided for in the general objectives of the PCNs. Therefore, despite the new reformulation of the political and educational standards of the discipline, there are still some difficulties encountered in its application in the school context

\section{Keywords: Education.School Physical Education.}

\section{Introdução}

A Educação Física (EF) é uma área de estudos que de forma relevante esteve presente em vários contextos históricos importantes do mundo, em cada um desses cenários ela ocupou um espaço e obteve um molde diferente, que variou, conforme os interesses políticos, econômicos e governamentais de uma determinada cultura ou população. Na totalidade desse processo é importante ressaltar que grande parte do destaque dado à EF, ocorreu devido à evolução e participação histórica nos espaços e sistemas educacionais escolares.

No contexto vigente a educação física utiliza o movimento como um meio de tratar o homem em sua totalidade. Segundo Barbanti (2003), atualmente na sociedade ocidental a EF e definida por vários autores como uma área de interesses amplos que trata o homem em toda a sua esfera abrangendo o movimento humano e as outras áreas da educação e o relacionamento do desenvolvimento físico com o mental, social e emocional na medida em que os mesmos vão sendo desenvolvidos.

Mas essa visão positiva e moderna nem sempre fez parte do histórico da $\mathrm{EF}$, principalmente no que diz respeito ao seu conceito e atuação dentro do processo educacional de formação nas escolas. No entanto, não é possível abordar, discutir, ou até mesmo entender qualquer viés dessa esfera das políticas públicas que envolvem o 
ensino desta disciplina no âmbito escolar sem antes voltar ao contexto que originou o panorama atual.

Quando a Educação Física passou a ser inserida como disciplina escolar, ela foi utilizada com um instrumento ideológico de manipulação das instituições militares que buscavam homens para defender os ideais da pátria, e da classe de médicos higienistas que buscavam melhorar os hábitos de higiene da população. E no Brasil também esteve ligada ao processo de higienização, e educação sexual para manter a pureza da raça branca, já que existiam muitos escravos. Como relata Ponce (1986), a educação é um dos métodos usados, pelo quais as classes dominantes preparam a mentalidade e a conduta das crianças.

No Brasil a EF, foi incluída como disciplina escolar em 1851, no entanto nessa época grande parte dos pais oferecia resistência em relação à participação de seus filhos nas aulas já que a corte ligava o esforço físico às atividades desenvolvidas por escravos, porém havia maior aceitação à participação dos meninos que a das meninas já que a ginástica estava associada às instituições militares, Brasil (1997).

Apesar de ser uma disciplina desenvolvida desde os tempos da corte, é no século XX que a Educação Física passa a ter um destaque maior no Brasil, devido ao processo de revolução industrial da década de 1930 e da influência da filosofia positivista de "Ordem e Progresso" ligada ao militarismo. No entanto Soares, (1994) relata em sua obra que a disciplina nessa época esteve ligada às raízes e parâmetros importados da revolução industrial da Europa, mais especificamente da França do século XIX, onde nasceram os primeiros conceitos de uma nova classe de homens, uma categoria saudável e com vigor físico, para o trabalho operário.

Após esse período onde o vínculo da disciplina no contexto escolar esteve meramente ligada aos fins dos processos de urbanização e industrialização das cidades, a educação física vivência um outro processo político, entre as décadas de 1950 e 1960 sobre as influências filosóficas positivistas de interesses militares surge no Brasil o método da Educação Desportiva Generalizada, de tendências européias constituindo em seu principal elemento a cultura corporal, que foi difundido no país por Auguste Listello, 
Caparroz, (1997). Esse período foi marcado por uma grande aceitação dos professores a tendência, e a educação física passou a ser subordina aos códigos e sentidos das organizações esportivas.

Mesmo com a atuação de cunho militar e desportivo da Educação Física das décadas de 50 e 60 sua participação nas escolas não era de caráter oficial nos currículos de educação nacional. Para Darido (1999), de fato a disciplina foi incluída oficialmente no currículo através da reforma de Couto Ferraz por meio da lei 4.024 de 1961, passando a ser obrigatória nas escolas para os alunos "até 18 anos de idade".

Durante década de 1970 a educação física esteve ligada às atividades esportivas, sendo considerada primordial para reforçar ainda mais os valores cívicos de ordem e progresso, surge também à ideia por parte do governo transformar o país em potência olímpica com intuito de proporcionar o "milagre econômico brasileiro", Brasil (1998).

Só durante a década de 1980 é que a Educação física se liberta desse ideal meramente tecnicista de caráter esportivo e militar, surgem às teorias psicológicas. E nessa reformulação algumas abordagens pedagógicas apareceram para se opor a esse modelo foram elas: Psicomotora, construtivista, desenvolvimentista e críticas, que se originaram de correntes e concepções psicológicas, sociológicas e filosóficas. E todas elas contribuíram de forma positiva para que a visão e os espaços sobre a Educação Física escolar aumentassem, os objetivos educacionais se amplificaram Brasil, (1998).

Foi em meio a todo esse processo conturbado que a disciplina nasceu dentro das escolas. Atualmente o cenário de ensino da Educação física escolar, possui uma política melhor estruturada, onde as suas fundamentações de amparo ao plano pedagógico de ensino escolar em todo o Brasil se encontram na Lei de Diretrizes e Bases de 1996 (LDB), e no Plano Nacional de Educação (PNE), que vigora por 10 anos, e visa à qualidade na educação de todas as disciplinas que fazem parte das formações básicas no contexto da escola. 
De acordo com Art. $26^{\circ}$ da LDB, (1996), os currículos de ensino médio e fundamental devem ter uma base nacional comum, tendo por completo o respeito, a cultura, local da sociedade a economia e a clientela. $\S 3^{\circ}$. A educação física deve ser componente curricular da Educação Básica ajustando-se as faixas etárias e as condições da população escolar, sendo facultativa aos cursos noturnos.

No Estado Minas Gerais os professores também contam com amparo da lei orgânica de 2009, que coloca a Educação física como disciplina curricular obrigatória, que deve ser praticada com os fins afetivos e cognitivos, estimulando turmas de iniciação esportiva para os alunos mais habilidosos.

No entanto através dos Parâmetros Curriculares Nacionais (PCNs), documento inspirado no modelo educacional espanhol, feito por um grupo de professores pesquisadores que foi lançado nos anos de 1997 e 1998, incluindo um documento especifico para área de educação física, que os professores obtiveram maior autonomia em suas aulas Brasil (1998). A educação física passou, portanto a ser embasada por uma nova concepção de ensino e prática corporal, além da esportiva, seus conteúdos também podem ser aplicados através da dança, ginástica geral, jogos e lutas e através delas e do próprio esporte exercer o seu papel de contribuição na formação da criança.

Tendo em vista todas essas etapas políticas e históricas de educação, o presente estudo teve como objetivo analisar a relação entre a eficácia dos conteúdos aplicados pelos professores nas aulas de educação física e os objetivos gerais dessa disciplina, no ensino fundamental, propostos pelo PCN.

\section{Quadro 1: Materiais e métodos}

População: Composta por 26 professores de educação física do ensino fundamental da Rede Pública de Ensino Municipal e Estadual de João PinheiroMG e Paracatu - MG.

Amostra: Foi composta por 26 professores de educação física dos anos finais do ensino fundamental, dos sexos feminino e masculino na faixa etária de 20 a 55 anos que trabalham nos turnos matutino e vespertino com carga horária de 18 
e 36 horas, de uma população de 45 professores de educação física do ensino fundamental.

Instrumento: Foi aplicado um questionário com quatorze questões fechadas referentes aos objetivos gerais da educação física no ensino fundamental.

Coleta dos dados: Nos períodos de 6 a 18 do mês de setembro 2019, feita em 7 escolas públicas do município de João Pinheiro - MG em área rural e urbana e 7 escolas públicas de Paracatu - MG.

Instrumento: Formulário do Google for Education

Elaborado pela autora (2019)

\section{Resultados e discussão}

Os resultados encontrados foram distribuídos da seguinte forma: na questão que envolve o sexo dos 34 professores participantes $64,7 \%$ da amostra apresentada foram do sexo masculino e $35,3 \%$ do sexo feminino, e a faixa etária, ficou entre o período de 20 a 60 anos. De acordo com as séries que os professores atuam: $6^{\circ}$ ano $22,7^{\circ}$ ano $16,8^{\circ}$ ano $11,9^{\circ}$ ano 10 .

De acordo com os resultados a maior parte dos professores da amostra está atuando no contexto escolar após a implantação dos parâmetros curriculares nacionais. (Ver Tabela $n^{\circ} 01$ ).

Tabela 01 - Demonstrativa do tempo de atuação dos professores no contexto escolar:

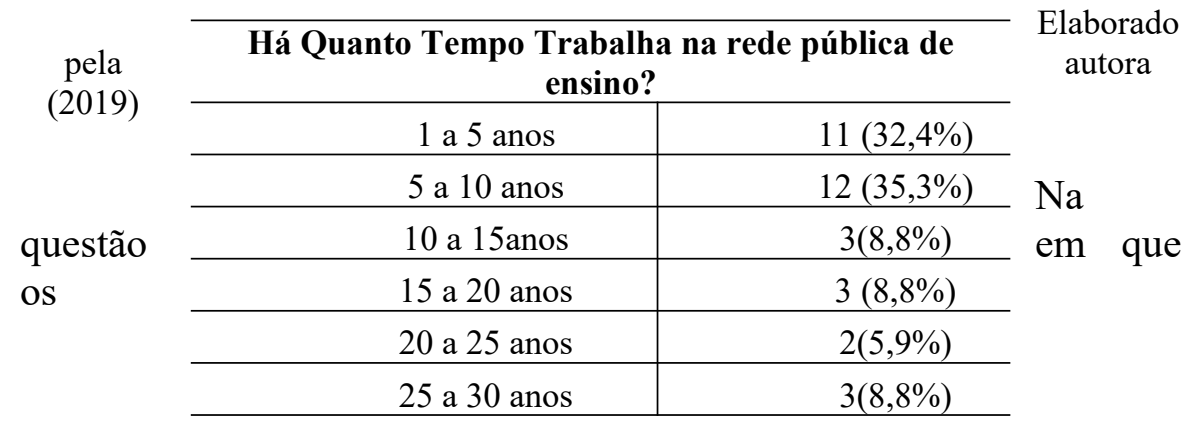

educadores classificam o próprio conhecimento referente ao processo histórico e contemporâneo das políticas públicas que envolvem o ensino da educação física escolar no Brasil os resultados obtidos foram: 
Tabela 02 - Relacionada ao conhecimento das políticas públicas educacionais do Brasil:

\begin{tabular}{c|c}
\hline \multicolumn{2}{c}{$\begin{array}{c}\text { Como você classifica o seu conhecimento sobre as } \\
\text { políticas públicas que envolvem o ensino da EF no } \\
\text { Brasil? }\end{array}$} \\
\hline Regular & $6(17,6 \%)$ \\
\hline Bom & $24(70,6 \%)$ \\
\hline Ótimo & $2(5,9 \%)$ \\
\hline Ruim & $2(5,9 \%)$ \\
Péssimo & $0(0 \%)$ \\
\cline { 2 - 2 }
\end{tabular}

Elaborado pela autora (2019)

A maioria dos professores pesquisados classificaram o próprio conhecimento como sendo bom, essa é uma variável bastante positiva, já que é por meio do entendimento desse processo que os educadores podem usar o senso crítico em relação ao verdadeiro significado de ensinar a educação física nas escolas.

Carmo (1985), aponta em sua obra que o professor de educação física precisa sempre buscar conquistar um nível de consciência crítica que lhe possibilite a compreensão mais ampla e clara do significado de sociedade, da Educação, da Escola, da Educação Física, de forma que venha perceber os fatores que limitam a sua postura e ação pedagógica, para assim, assumir uma postura crítica e desenvolver a sua atuação com competência técnica aliada a uma consciência política.

Os professores que classificaram o próprio conhecimento como sendo regular, ótimo e ruim perfazem $29,4 \%$ da amostra sendo que os indivíduos que qualificaram o próprio entendimento como regular totalizam maior parte em relação aos que o se consideraram como ótimos e ruins em domínio e entendimento das políticas públicas de ensino da EF.

Independente do conhecimento que cada professor julga ter, é imprescindível lembrar que, são os professores que atuam no contexto escolar que participam da formação, intelectual e crítica dos alunos e da comunidade, em relação ao aprendizado e ao nível de importância e relevância social que determinada disciplina ou área de

Educação In Loco, v.01, n. 01, jan.-jun. 2020 
estudos pode contribuir ou se fazer necessária dentro dos padrões políticos e sociais de uma determinada cultura.

Segundo Savani (1996:24) [...] os professores inserem-se na organização do conhecimento e definem o que é possível de ser ensinado/aprendido em sua disciplina, bem como o lugar e o valor no currículo.

Em relação aos conteúdos aplicados com mais frequência durante as aulas os resultados obtidos foram:

Tabela 03 - Relacionada aos conteúdos aplicados com mais frequência nas aulas:

\begin{tabular}{cc|c}
\cline { 2 - 3 } pela & \multicolumn{2}{c}{$\begin{array}{c}\text { Qual (is) desse (s) conteúdo (s) você aplica } \\
\text { com mais frequência nas suas aulas? }\end{array}$} \\
$(2019)$ & $\begin{array}{c}\text { Elaborado } \\
\text { autora }\end{array}$ \\
\cline { 2 - 3 } *Esses & Esportes & $27(79,4 \%)$ \\
\cline { 2 - 3 } & Jogos & $14(41,1 \%)$ \\
\cline { 2 - 3 } & Ginásticas & $7(20,5 \%)$ \\
\cline { 2 - 3 } & Danças & $3(8,8 \%)$ \\
\hline Lutas & $3(8,8 \%)$ \\
\hline
\end{tabular}

ultrapassam $\mathbf{1 0 0 \%}$ porque cada professor poderia marcar mais de uma das alternativas.

Mesmo sendo explicitados nos PCNs de 1997 e 1998, que temas diferentes podem ser abordados e trabalhados durante as aulas, nota-se pelo resultado da pesquisa que ainda há uma preferência muito grande por parte dos professores em aplicar conteúdos de caráter esportivo, mostrando assim que apesar de todos esses anos a educação física ainda sofre muita influência do processo de esportivização sofrido nos anos de 1950. No entanto é importante ressaltar que as aulas não podem de maneira alguma trazer no seu objetivo a formação de atletas, pois a disciplina na escola tem em seu processo, o alvo de inclusão dos alunos. Segundo Oliveira, (1995) O objetivo de formar campões não é da educação física escolar como componente curricular uma vez que visa à formação integral do aluno e de todos sem discriminação.

Os jogos ficaram com o segundo lugar entre os conteúdos mais abordado nas aulas, esse é um fator positivo. Segundo Betti, 
(1992) eles constituem quando bem aplicados uma boa estratégia de ação podem ser de competição, cooperação, sequências pedagógicas, demonstração, descobrimento guiado, resolução de problemas, jogos de mímica e expressão corporal, grandes jogos, jogos simbólicos, jogos rítmicos, exercícios em duplas, trios, grupos, com e sem material, circuito, aulas com música, aulas historiadas, jogos prédesportivos, gincanas, campeonatos, festivais.

A ginástica ficou em terceiro lugar em relação aos conteúdos abordados nas aulas, é importante lembrar que assim como o esporte a prática da ginástica no âmbito escolar também influenciou muito no o processo político histórico da disciplina "Relembrando. No Brasil os elementos da cultura corporal/movimento predominantes na Educação Física foram. Num primeiro momento. A ginástica e, num segundo - e esta é a situação atual - o esporte" (BRACHT, 1992).

As Danças e Lutas alcançaram um índice baixo de aplicação nas aulas ocupando o quarto lugar, no entanto a dança e a luta além de desenvolverem de forma diferente os movimentos podem trabalhar nas crianças a expressão e a criatividade dos movimentos corporais. Mas ainda há na comunidade escolar uma resistência em trabalhar esses conteúdos talvez pela resistência aos movimentos mais extenuados que o corpo expressa dançando e lutando. Segundo Arruda (1988), os adultos possuem certa resistência ao movimento e reprimem a soltura das crianças, esse conceito começa em casa e se prolonga nas escolas.

Mesmo sobre forte influência de conteúdos como esporte, jogos e ginástica há necessidade que os professores busquem trabalhar em suas aulas, a educação física que proporcione a formação de cidadania do aluno, trabalhando os aspectos físicos, sociais e cognitivos, buscando assim uma autonomia e processos que levem a qualidade de vida. "A integração que possibilitará o usufruto da cultura corporal de movimento há de ser plena - é afetiva, social, cognitiva e motora. Vale dizer, é a integração de sua personalidade" (Betti, 1994).

Entre as oito questões referentes aos objetivos gerais da EF no ensino fundamental explicitados nos PCNs de educação física no ensino fundamental e a percepção especifica e geral dos professores 
em relação à aplicabilidade política e geral dos mesmos nas escolas públicas os resultados obtidos foram os descritos no quadro 2 :

QUADRO 2 - Relacionado à percepção dos professores ao processo de formação e aprendizagem dos alunos referente aos objetivos dos PCNs.

\begin{tabular}{|c|c|c|c|}
\hline DESCRICAO & $\begin{array}{c}\text { CONCORDO } \\
\text { PLENAMENTE }\end{array}$ & $\begin{array}{c}\text { CONCORDO } \\
\text { PARCIALMENTE }\end{array}$ & $\begin{array}{c}\text { DISCORDO } \\
\text { PLENAMENTE }\end{array}$ \\
\hline $\begin{array}{c}\text { Nível de conhecimento e } \\
\text { aceitação corporal }\end{array}$ & $23,50 \%$ & $73,50 \%$ & $3 \%$ \\
\hline $\begin{array}{c}\text { Relação interpessoal, } \\
\text { respeito mútuo }\end{array}$ & $20,50 \%$ & $76,50 \%$ & $3 \%$ \\
\hline $\begin{array}{c}\text { Valorização respeito da } \\
\text { cultura corporal }\end{array}$ & $20,50 \%$ & $79,50 \%$ & $0 \%$ \\
\hline $\begin{array}{c}\text { Hábitos de higiene e } \\
\text { alimentação }\end{array}$ & $20,50 \%$ & $76,50 \%$ & $3 \%$ \\
\hline $\begin{array}{c}\text { Resolução de problemas e } \\
\text { ordem corporal }\end{array}$ & $29,40 \%$ & $67,60 \%$ & $3 \%$ \\
\hline $\begin{array}{c}\text { Reconhecer condições de } \\
\text { trabalho digna }\end{array}$ & $20,50 \%$ & $64,80 \%$ & $6 \%$ \\
\hline $\begin{array}{c}\text { Análise crítica de padrões } \\
\text { estéticos }\end{array}$ & $26,50 \%$ & $67,60 \%$ & $6 \%, 50 \%$ \\
\hline $\begin{array}{c}\text { Reconhecer os direitos do } \\
\text { cidadão }\end{array}$ & $41,10 \%$ & $52,90 \%$ & $6 \%$ \\
\hline
\end{tabular}

Elaborado pela autora (2019)

As variáveis que avaliaram a percepção dos professores em relação ao nível conhecimento fornecido durante as aulas para os alunos foram medidas de acordo com as seguintes afirmativas: Concordo plenamente, concordo parcialmente, discordo plenamente.

$\mathrm{Na}$ questão em que os educadores avaliaram se os conteúdos aplicados são capazes de proporcionar um bom nível de

Educação In Loco, v.01, n. 01, jan.-jun. 2020 
conhecimento e aceitação corporal para os seus alunos, a maior parte dos pesquisados concordou parcialmente com a afirmativa, a aceitação corporal e os respeito às limitações, ocorre devido à imagem corporal que cada um tem de si mesmo.

Segundo Becker (1999), as pessoas começam a avaliar seus corpos através da interação com o ambiente, assim a autoimagem é desenvolvida e reavaliada continuamente durante toda a vida. Nesse aspecto pode-se observar o quanto e importe que o professor trabalhe em suas aulas conteúdos que proporcione aos alunos a construção de relações equilibradas com o meio com si próprio e com os demais colegas.

Ainda sobre o tema de aceitação corporal uma porcentagem menor concordou plenamente que os conteúdos aplicados durante as aulas de EF, são capazes de desenvolver todas essas valências em seus alunos. De acordo com LDB (1996) as aulas devem enfatizar um trabalho de diversidade das competências corporais aprendendo assim sobre o próprio desempenho e sobre o desempenho dos colegas, sem discriminar pelo sexo, ou por deficiências físicas. No entanto a uma pequena parte dos entrevistados discordou plenamente da afirmativa. Segundo Tavares (2003), o conceito de imagem corporal está vinculado aos significados dos termos, não é simplesmente uma questão de linguagem possui uma dimensão muito maior se classificarmos cada indivíduo e sua subjetividade. Talvez caiba aos professores procurar uma nova forma de trabalho que consiga de maneira eficaz abranger parte dessa singularidade de seus alunos.

Em relação à variável que aborda o nível de respeito mútuo dos alunos e atitudes de respeito e solidariedade em situações lúdicas se esportivas repudiando qualquer espécie de violência à maioria dos professores concordou parcialmente. Essa característica está ligada aos conteúdos mais aplicados pelos professores das pesquisas o esporte e os jogos PCNs (1997), apontam que as atividades competitivas realizadas nas aulas são favoráveis para o exercício de diversos papéis, estilos pessoais, promovendo o melhor conhecimento de si mesmo e o respeito de si mesmo e dos outros. Os demais professores concordaram plenamente, o que implica que 
apesar da competição esportiva ainda ser um dos conteúdos mais aplicados, alguns educadores estão conseguindo abordar o tema trabalhando toda a riqueza que o mesmo pode trazer para os alunos. Uma pequena parcela discordou plenamente o que indica que para esses professores conteúdos relacionados apenas com o desporto não são plenamente eficazes para os seus alunos.

A maior preocupação em relação ao esporte dentro das aulas de educação física e a maneira que o mesmo e abordado, pois ele precisa ser inclusivo, em sua obra Bracht (1992), aponta que por vezes os papéis se confundem o professor passa ser treinador e o aluno passa ser o atleta, uma vez que não pode ser confundida à definição do papel do professor de Educação Física.

Em relação ao respeito à valorização da cultura corporal e as diversas manifestações e pluralidade de cultura do Brasil e do mundo grande parte dos professores concordaram parcialmente. Uma das prioridades de que devem ser trabalharam nas aulas e a valorização da cultura, PCNs (1997) aponta que as manifestações da cultura corporal estão presentes desde a formação da cultura humana, e que algumas dessas manifestações antropológicas foram inseridas a EF, escolar pelos seus conteúdos e essa percepção de manifestações culturais devem ocorrer nas atividades de forma lúdica à medida que os conteúdos são aplicados.

Os demais educadores concordaram plenamente que os seus alunos são capazes de absorver e aplicar com consciência e respeito os valores da cultura corporal, o que é de suma importância e relevância, pois é através dessa estimação que se pode alcançar a inteligência do corpo e da mente. Freire (1989) descreve em sua obra que quem faz e pensa e o próprio corpo. As produções físicas e intelectuais são, portanto, produções corporais. Produções essas que se dão nas interações do indivíduo com o mundo.

Entre a questão que aponta o conhecimento obtido nas aulas e a adoção de hábitos saudáveis de higiene alimentação e atividades corporais, relacionando os efeitos da mesma com a melhoria da própria saúde e das dos demais, a grande maioria dos professores concordou parcialmente. Os demais concordaram e discordaram plenamente. 
Em sua obra Rocha (2003) relata que, a escola, o exemplo do professor, as práticas de higiene e o conhecimento das questões relativas à higiene tornaram-se os elementos capazes de influir na atividade infantil. Brasil (1997) aponta que, o conhecimento sobre o corpo, durante os processos de crescimento e desenvolvimento das práticas corporais dá subsídios aos indivíduos ao cultivo de bons hábitos de alimentação e higiene.

Em relação aos aspectos relacionados com a resolução de problemas de ordem corporal a maioria dos educadores concordaram parcialmente, PCNs (1997) aponta que as aulas lúdicas competitivas ou não favorecem e oportunizam aos alunos diferentes problemas a resolver, pois a gama de movimentos que podem ser empregados nas atividades é muito grande.

Os demais professores concordaram plenamente, mostrando um fator positivo, pois se os seus alunos são inteiramente capazes de resolver os problemas que aparecem nas atividades poderão também analisar e solucionar de forma mais prática algumas situações do cotidiano, utilizando muitas vezes o fator de cooperação. Um número muito pequeno entre os pesquisados apontou que os conteúdos aplicados não são capazes de ajudar os alunos nas resoluções dos problemas de ordem corporal. Segundo Betti, (1992) a educação física deve dar autonomia progressiva ao aluno levando o mesmo a ter usufruto dos elementos da cultura corporal do movimento.

Sobre a questão que julga o reconhecimento dos alunos as condições de vida e trabalho dignos, a maioria dos pesquisados respondeu que concordam parcialmente que os conteúdos das aulas podem interferir nesse julgamento dos alunos, segundo Brasil (1997), em oposto aos conceitos passados da educação física, hoje a disciplina e responsável pela formação do corpo vivo e de todas as suas dimensões cultural, social, política e afetiva, trazendo aos alunos um censo crítico em relação à sociedade, transformando os mesmo em cidadãos que reivindicam os seus direitos.

Ainda referente aos padrões de trabalho e vidas dignas os outros professores se dividiram em concordarem e discordarem plenamente, gerando uma pequena diferença de percentual entre as duas afirmativas. A maior preocupação nesse caso seria com os 
educadores que não conseguem ainda atingir durante as aulas o senso crítico de seus alunos em relação às questões ligadas a sociedade e a cidadania.

Oliveira (2000) adverte, o caminho que leva à construção desta sociedade implica um processo gigantesco de educação, e não apenas a educação entendida no sentido da transmissão do conhecimento, mas no sentido da formação da cidadania.

Em relação à questão que envolve e relaciona as aulas ao nível de conhecimento critico dos alunos aos padrões estéticos de saúde beleza, de diferentes culturas e os valores impostos pela mídia, grande parte dos educadores afirmou concordar parcialmente com o objetivo. Os PCNs (1997), aborda que, os conhecimentos construídos nas atividades devem possibilitar aos educandos análise crítica dos valores sociais, e dos padrões de beleza da cultura em que estão inseridos e das demais culturas respeitando pelos pontos de vista, sem discriminação social ou por raça, assumindo posturas nãoconsumistas, não-discriminatórias, não-preconceituosas.

Os demais professores se dividiram entre e concordo plenamente e discordo plenamente sendo que os que discordam se repartem em uma parcela muito pequena, o que tornam os resultados satisfatórios já que os padrões estéticos da sociedade ocidental têm causado principalmente nas crianças e nos jovens problemas de ordem emocional e funcional. De acordo com Tavares (2003), somos pressionados em numerosas circunstâncias a concretizar, em nosso corpo, o corpo ideal de nossa cultura.

Já entre a questão que implica o conhecimento adquirido e a relação entre conhecer e organizar e interferir nos espaços de forma autônoma, bem como reivindicar locais adequados para promover atividades corporais de lazer, reconhecendo-as como uma necessidade básica e direitos do cidadão, pouco mais da metade dos educadores concordou de forma parcial. Conforme aponta dos documentos pesquisados (PCN, 1997), as atividades que envolvem a ludicidade e os esportes não são direito apenas dos atletas por isso a partir do momento em que os alunos adquirem o conhecimento devido sobre as práticas corporais os mesmo passam a reivindicar 
espaços para prática desportiva fazendo o uso dos seus direitos á cidadania.

Quase metade dos entrevistados concordou plenamente com a questão e uma pequena parte discordou da afirmativa. Aos professores que identificam em seus alunos o reconhecimento a cidadania e os interesses pela prática desportiva, e importante ressaltar o mérito que à cultura do movimento pode ter quando apresentada de forma correta aos alunos pois refletira em ações sociais. Aos educadores que discordaram plenamente da afirmativa, vale lembrar que um dos maiores intuitos da educação no geral é trazer o aluno ao exercício pleno da cidadania se isso não está acontecendo e preciso que os professores revejam o próprio conceito.

Segundo Nogueira, (2000) a educação para cidadania requer muito mais do que a simples criação de oportunidades de participação dos alunos em alguns eventos proporcionados pela escola. Para que haja educação que forme cidadãos, é necessário que os indivíduos possam dialogar e dizer os seus anseios e necessidades para que assim a escola seja vista como um local de troca de relacionamentos, e não de imposições de regras que por vezes não condizem com a realidade.

\section{Considerações Finais:}

Após a análise dos dados pode-se concluir que grande parcela dos educadores pesquisados concorda parcialmente com os efeitos das aulas de Educação Física, em relação à formação de seus alunos prevista nos objetivos gerais do PCN (1997). Portanto apesar da nova reformulação dos padrões políticos e educacionais da disciplina, há ainda algumas dificuldades encontradas em sua aplicação no contexto escolar.

Os resultados encontrados entre os professores que concordam e discordam plenamente com a eficácia das aulas, foi menor do que parcialmente, no entanto, é importante ressaltar que apesar das dificuldades apontadas, alguns educadores, já conseguem atingir plenamente os objetivos curriculares da Educação Física no ensino fundamental, mas infelizmente há alguns que não atingem, de 
forma alguma, os objetivos didáticos da educação, seja por deficiência de didática, conhecimento ou até mesmo por problemas relacionados à formação acadêmica.

Para uma melhor investigação sobre as políticas públicas de ensino e seus efeitos educacionais sobre os professores e alunos, sugere-se que haja mais trabalhos referentes a esses estudos.

\section{Referências:}

ARRUDA, Solange. Arte do movimento. São Paulo: PW Gráficos e Editores Associados 1tda., 1988.

BARBANTI, V.J. Dicionário de educação física e esportes, Barueri Editora Manole Ltda., 2003.

BETTI, M. Educação Física para quê? Revista Brasileira de Ciências do Esporte, v. 13, n. 2, p. 282-7, 1992.

BETTI, M. Valores e finalidades na Educação Física escolar: uma concepção sistêmica. Revista Brasileira de Ciências do Esporte, v. 16, n. 1, p. 14-21, 1994.

BRACHT, V. Educação Física e aprendizagem social. Porto Alegre: Magister, 1992.

BRASIL, Ministério de Educação e do Desporto. Parâmetros Curriculares Nacionais: terceiro e quarto ciclos: Educação Física / Secretaria de Ensino Fundamental. Brasília: MEC/SEF, 1998.

BRASIL, Ministério de Educação e do Desporto. Parâmetros Curriculares Nacionais: Educação Física/ Secretaria de Ensino Fundamental. Brasília: MEC/SEF,1997.

BRASIL: Lei de Diretrizes e Bases da Educação Nacional, Lei ${ }^{\circ}$ 9.394, de 20 de dezembro de 1996.

CARMO, Apolônio A. do. Educação Física: competência técnica e consciência política em busca de um movimento simétrico. Uberlândia: Universidade Federal de Uberlândia, 1985.

CAPARROZ, Francisco Eduardo. Entre a Educação Física na Escola e a Educação Física da Escola. Vitória: UEFES, Centro de Educação Física e Desportos, 1997. 
DARIDO, Suraya Cristina. Educação Física na Escola: questões e reflexões. Araras, Topázio, 1999.

FREIRE, João Batista. Educação de Corpo Inteiro: Teoria e prática da Educação Física. São Paulo: Scipione. 1989.

MINAS GERAIS. Metodologia do ensino de Educação Física. Minas Gerais, 1990.

MINAS GERAIS. Manual de Psicologia aplicada ao Exercício \& Esporte. 1990

NOGUEIRA, I. A violência nas escolas e o desafio da educação para a cidadania. Trabalho apresentado na $23^{\mathrm{a}}$. Reunião Anual da ANPED, Caxambú, 2000.

OLIVEIRA, Amauri A.B. A Formação Universitária em Educação Física. Revista Brasileira de Ciências do Esporte, Santa Maria. V.16, n.3, p.209-212, mai. 1995.

OLIVEIRA, I. A. R. Sociabilidade e direito no liberalismo nascente. Revista Lua Nova, n. 50, p. 160, 2000, v. II.

PONCE, Aníbal. Educação e luta de classes. 6ed., São Paulo: Cortez, 1986.

ROCHA, H.H.P. A higienização dos costumes: educação escolar e saúde no projeto do Instituto de Higiene de São Paulo (1918-1925). Campinas, SP: Mercado de Letras, São Paulo: Fapesp, 2003 a.

SAVANI, Demerval. Saber escola, currículo e didática: problemas da unidade conteúdo/método no processo pedagógico. Campinas: Autores Associados, 1994.

SOARES, Carmen Lúcia. Educação física: raízes Europeias e Brasil. Campinas: Autores Associados, 1994.

TAVARES, M.C.C. Imagem Corporal: Conceito e Desenvolvimento. São Paulo: Manole. 2003. 